\title{
La Administración local en el Principado de Asturias: relaciones con la Comunidad Autónoma
}

Juan Luis de la Vallina Velarde

Catedrático de Derecho Administrativo

SUMARIO: I. CONSIDERACIÓN PREVIA. II. LA DISTRIBUCIÓN COMPETENCIAL CONSTITUCIONAL EN MATERIA DE ADMINISTRACIÓN LOCAL. III. EL PRINCIPADO DE ASTURIAS COMO COMUNIDAD AUTÓNOMA UNIPROVINCIAL. IV. LEGISLACIÓN AUTONÓMICA DEL PRINCIPADO DE ASTURIAS SOBRE ADMINISTRACIÓN LOCAL. 1. Regulación de comarcas. 2. Demarcación territorial de los Concejos. 3. La Parroquia rural. V. TIPOLOGÍA DE LAS RELACIONES DE LAS ENTIDADES LOCALES CON LA COMUNIDAD AUTÓNOMA DEL PRINCIPADO DE ASTURIAS. 1. Manifestaciones de relaciones de cooperación. 1.1. Cooperación a obras y servicios de competencia municipal. 1.2. Comisión Asturiana de Administración local. 1.3. Sociedad de Servicios del Principado de Asturias S.A. 1.4. Red asturiana de Desarrollo local. 1.5. Asistencia letrada a municipios. 1.6. Convenios de colaboración y entidades consorciales. 1.7. Delegación intersubjetiva de competencias. 1.8. Colaboración en el ámbito urbanístico. 2. Relaciones de coordinación. 2.1. La Ley 6/1988, de Coordinación de Policías locales. 2.2. Coordinación urbanística: la ordenación del territorio. 3. Relaciones en orden a la iniciativa legislativa municipal respecto de competencias autonómicas.

\section{CONSIDERACIÓN PREVIA}

El Principado de Asturias, como en general todas las Comunidades Autónomas, ha asumido estatutariamente la competencia sobre régimen local. En este caso «en el marco de la legislación básica del Estado... el desarrollo legislativo y ejecución» (art. 11.10 EA); aparte de corresponderle como competencia exclusiva, en base al artículo 148.2 CE., «la alteración de los términos y denominación de los concejos comprendidos en su territorio, así como la creación de organizaciones de ámbito inferior y superior a los mismos...» (art. 10.2 EA) ${ }^{1}$.

Territorialmente la Comunidad Autónoma asturiana se organiza en «municipios que recibirán la denominación tradicional de Concejos y en

\footnotetext{
${ }^{1}$ Esta atribución competencial, en la actual redacción, es consecuencia de la segunda reforma estatutaria operada por L O 1/1999, de 5 de enero: hasta esta fecha el Principado de Asturias, en cuanto Comunidad Autónoma constituida por la vía del art. 143 CE, carecía de competencia legislativa plena respecto de las entidades locales de su territorio, fuera de las competencias atribuidas en base a lo dispuesto en el art. 148.1.2. CE.
} 
comarcas» (art. 6.1. EA), no contando con el ente local provincial al tratarse de una Comunidad Autónoma uniprovincial. Los municipios asturianos en número de 78 presentan, por regla general, una cierta dimensión territorial y poblacional, aunque con la peculiaridad de contar en gran medida con núcleos diseminados de población, como característica de los asentamientos humanos en el noroeste peninsular ${ }^{2}$, dando lugar desde el punto de vista institucional «a la parroquia rural como forma tradicional de convivencia y asentamiento de la población asturiana» (art. 6.2 EA) ${ }^{3}$.

\section{LA DISTRIBUCIÓN COMPETENCIAL CONSTITUCIONAL EN MATERIA DE ADMINISTRACIÓN LOCAL}

La existencia de un Estado compuesto como nuestro Estado de las Autonomías plantea la gran cuestión de determinar el poder territorial al que corresponde la competencia para regular el régimen local. Se trata, como decía el Prof. Guaita, de uno de los asuntos «más tentadores para las nuevas autonomías territoriales» ${ }^{4}$. Por ello no es de extrañar que desde los comienzos de los debates constitucionales quedase planteada la cuestión con una evidente carga política y que las tensiones y puntos de vista encontrados tengan su lógico reflejo en la redacción del texto de la Constitución. La situación se resolvió con lo que podemos considerar como silencio intencionado del constituyente. No existe una atribución expresa de la competencia legislativa sobre el régimen local a favor de ninguno de los poderes territoriales. Únicamente, el artículo 148.1.2. se refiere a la legislación de régimen local al permitir que todas las Comunidades Autónomas puedan asumir las funciones que corresponden a la Administración del Estado y cuya transferencia autorice dicha legislación de régimen local; precepto en el que S. MarTín-RETORTILLO quiere ver un

\footnotetext{
${ }^{2}$ Con carácter general sobre esta forma de asentamiento de la población, conectada con la historia de nuestras colectividades locales, vid. L. Morell Ocaña, Régimen local español (Madrid 1988) pp. 307 ss.; para Galicia vid. J. L. MeILÁn GIL y J. RodríGuez-Arana, «Asentamientos de la población y ordenamiento jurídico gallego», en Rev. de Estudios de la Administración Local y Autonómica (REALA) n. ${ }^{\circ}$ 244, pp. 751 ss.
${ }^{3}$ La existencia de estos núcleos rurales se encuentra especialmente reconocida y protegida por la normativa autonómica referente a la ordenación del territorio y urbanismo, desde la Ley 6/1990, de 20 de diciembre, sobre Edificación y Usos en el Medio Rural, hasta la Ley 3/2002, de 19 de abril, de Régimen del Suelo y Ordenación urbanística. Esta última ley señala en su preámbulo que «la ley urbanística asturiana ha utilizado el margen de que dispone el legislador autonómico, para dar cabida a las formas de asentamiento humano características de Asturias, que configuran un peculiar sistema de población de su territorio».

${ }^{4}$ A. Guaita, «Competencias del Estado y las Comunidades Autónomas en materia de Administración local», en Homenaje a Carlos Ruiz del Castillo (Madrid 1985), p. 284.
} 
inequívoco título competencia! en favor del Estado ${ }^{5}$ y que, por otro lado, ha sido valorado como una declaración donde «existe latente un resabio de arrinconar cualquier atisbo de orden federalista» ${ }^{6}$.

Sin duda, algún sector de los constituyentes quiso aplicar en este caso el precedente de 1931. La Constitución de la II República no atribuía la competencia sobre las Administraciones locales ni al Estado ni a las Regiones, por lo que podía llegar a ser asumida por estas últimas plenamente, por medio de sus respectivos Estatutos. Ésta es precisamente también la fórmula de la Ley Fundamental de Bonn, que tanto ha influido en nuestro texto constitucional; esta posición adoptada por la Constitución alemana es lo que ha permitido, en virtud del juego de la cláusula residual, otorgar a los Länder la titularidad de la competencia sobre las entidades locales ${ }^{7}$.

El vacío constitucional del texto de 1978, claramente intencionado, queda sin embargo cubierto por la cláusula competencial que otorga al Estado el artículo 149.1.18 CE para regular «las bases del régimen jurídico de las Administraciones públicas...que en todo caso garantizarán a los administrados un tratamiento común ante todas ellas», así como por la garantía constitucional de la autonomía local ${ }^{8}$. No sin cierta resistencia, ya que la carga política del asunto no facilitaba su pacífica comprensión y aceptación, fue abriéndose paso la tesis de que dicha previsión constitucional habilitaba al Estado para llevar a efecto la ordenación básica del régimen local, sin perjuicio de la competencia que sobre ese ámbito pueda corresponder a las Comunidades Autónomas de conformidad a sus respectivos Estatutos.

Partiendo de dicha interpretación, que fue implícitamente compartida por el Tribunal Constitucional (inicialmente en su sentencia de 2 de

\footnotetext{
${ }^{5}$ S. Martín-Retortillo, «La actuación de las Corporaciones locales. Acotaciones al proyecto de ley de regulación de las bases de régimen local», en Homenaje a C. Ruiz del Castillo (Madrid 1985), p. 365.

${ }^{6}$ J. M. CASTELls, «El municipio en la autonomía política», en Documentación administrativa n. ${ }^{\circ}$ 182 , p. 483.

${ }^{7}$ Cfr. S. Muñoz Machado, Derecho público de las Comunidades Autónomas II, (Madrid 1984), pp. 185-186.

${ }^{8}$ La competencia del Estado para la regulación básica del régimen local encuentra su apoyatura jurídica no solo en el mencionado artículo 149.1.18 CE, sino y sobre todo, como mantiene la STC 32/1981, de 28 de julio y reitera la STC 214/1989, de 21 de diciembre, en el hecho de que la «garantía constitucional es de carácter general y configuradora de un modelo de Estado y ello conduce, como consecuencia obligada, a entender que corresponde al mismo la fijación de los principios o criterios básicos en materia de organización y competencias» (STC 214/1989 FJ. 1).
} 
febrero de 1981 al resolver el recurso sobre la inconstitucionalidad sobrevenida de la legislación de régimen local de 1950-1955 y de manera definitiva y expresa en sus sentencias de 28 de julio de 1981, referente a las competencias de las Diputaciones catalanas y de 5 de agosto de 1983 sobre la LOAPA), dispone el Estado de competencia para la regulación del régimen local básico, cuya ejecución y desarrollo normativo puede ser asumido por las Comunidades Autónomas en sus respectivos Estatutos; bien entendido que esta competencia autonómica, de conformidad a la Constitución (arts. 148-149), sólo podía ser inicialmente recogida por los Estatutos de aquellas Comunidades con mayor nivel de autonomía ${ }^{9}$. Las restantes Comunidades Autónomas sólo disponían de las competencias a que se refiere el artículo 148.1.2. (alteración de términos municipales y en general aquellas funciones propias de la Administración del Estado cuya transferencia autorice la legislación de régimen local) ${ }^{10}$.

Con posterioridad y como efecto de las reformas estatutarias que ampliaron el techo competencial de las Comunidades Autónomas del artículo $143 \mathrm{CE}$, todas ellas disponen de competencia legislativa sobre las Administraciones locales de su territorio. Por ello, la regulación de la Administración local presenta ese carácter bifronte al que se ha referido el TC, sin que, por tanto, pueda ser calificado el régimen local de forma unívoca de intracomunitario o extracomunitario (STC 64/1982 FJ4).

\section{EL PRINCIPADO DE ASTURIAS COMO COMUNIDAD AUTÓNOMA UNIPROVINCIAL: LA INEXISTENCIA DEL ENTE LOCAL PROVINCIAL}

Admitida constitucionalmente la posibilidad de que una sola provincia «con entidad regional histórica» (art. 143.1 CE) pueda constituirse como

\footnotetext{
${ }^{9}$ Sólo podían disponer de esta competencia legislativa las denominadas Comunidades históricas (Disposición Transitoria Segunda de la Constitución), las que accedieron a la autonomía por el procedimiento previsto en el art. $151 \mathrm{CE}$, así como Canarias y Valencia en virtud del aumento del techo competencial producido por las Leyes Orgánicas 11/1982 y 12/1982, de 10 de agosto y la Comunidad Foral de Navarra según reconoce su régimen paccionado recogido en L.O. 13/1982, de 10 de agosto.

${ }^{10} \mathrm{Al}$ referirse el precepto constitucional a «funciones que correspondan a la Administración de Estado» es claro que en ningún caso puede entenderse que se trata de funciones legislativas, al margen de aquellas referentes a la alteración de términos municipales cuya asunción estatutaria se encuentra amparada por el art. 148.1.2. CE.
} 
Comunidad Autónoma ${ }^{11}$, quedaba abierta en estos supuestos la situación de la provincia como entidad local ${ }^{12}$.

Partiendo de considerar a la entidad local provincial como institución indispensable por expreso reconocimiento de la norma constitucional (art. 141.1 CE), podía defenderse su coexistencia con la Comunidad Autónoma; no obstante, ello debería ser descartado en cuanto que supondría la existencia de dos entidades territoriales con competencias sobre una misma población y territorio. Así fue entendido desde un principio, como se pone de manifiesto en el Informe de la Comisión de Expertos sobre Autonomías ${ }^{13}$ y se recoge en la LOAPA (art. 15), pasando a ser contenido de la Ley 12/1983, de 14 de octubre, del Proceso Autonómico (art. 9) con la siguiente redacción:

«1. En las Comunidades autónomas uniprovinciales que se constituyan, la Diputación provincial quedará integrada en ellas, con los siguientes efectos:

a) Una vez constituido el órgano de representación y gobierno de la Comunidad autónoma o en el momento que establezcan los respectivos Estatutos, quedarán disueltos de pleno derecho los órganos políticos de la Diputación.

b) La Administración provincial quedará totalmente integrada en la administración autonómica.

c) La Comunidad autónoma, además de las competencias que le corresponda según su Estatuto, asumirá la plenitud de las competencias y recursos que en el régimen común correspondan a la Diputación provincial

d) La Comunidad autónoma se subrogará en las relaciones jurídicas que se deriven de las actividades anteriores de la Diputación provincial.

2. Las Comunidades autónomas uniprovinciales tendrán además el carácter de Corporación representativa a que se refiere el artículo 141.2 de la Constitución» ${ }^{14}$.

La fórmula fue admitida como constitucionalmente correcta por el Tribunal Constitucional en su sentencia 76/1985, de 5 de agosto, recaída en

\footnotetext{
${ }^{11}$ Cfr. L. López Rodó, «La provincia en las Comunidades uniprovinciales y en Canarias», en Homenaje a C. Ruiz del Castillo (Madrid 1985), pp. 285 ss. Sobre el debate parlamentario respecto a la cuestión, vid. J. L. MarTínez López-MuÑIZ, «Provincia-entidad local y Comunidades autónomas uniprovinciales», en Rev. Estudios de la Vida Local n. ${ }^{\circ} 209$, pp. 30 ss.

${ }^{12}$ A la polémica que suscitaba la cuestión se refiere R. Bocanegra SIERRA, en Comentarios al Estatuto de Autonomía de la Comunidad Autónoma del Principado de Asturias, (Madrid 1987), p. 202 (comentario al art. $20 \mathrm{EA}$ ).

${ }^{13}$ Vid. dicho Informe en Legislación sobre Comunidades Autónomas (Ed. Tecnos 1982), p. 440.

${ }^{14} \mathrm{El}$ precepto de forma más concisa se reitera en el artículo 40 LBRL.
} 
el recurso previo de inconstitucionalidad contra la LOAPA ${ }^{15}$, considerando que así se recogía «explícita o implícitamente en los Estatutos de las Comunidades - todos ellos posteriores al texto inicial del proyecto (así, en los de Asturias, art. 29 y Disposición Transitoria Segunda, cuatro; Cantabria, art. 31 y Disposición Transitoria Tercera; Madrid, Disposición Transitoria Cuarta; Murcia, art. 18 y Disposición Transitoria Segunda y La Rioja, art. 14 y Disposición Transitoria Primera) y el valor del mismo para un futuro legislador estatutario no sería otro que una simple directriz que podría seguir o no libremente» (STC 76/1985, FJ. 18) ${ }^{16}$.

No obstante, el criterio utilizado con la supresión pura y simple de la entidad provincial y la asunción de sus competencias por las instituciones autonómicas, tal como se recogía en el artículo 20 y Disposición Transitoria Segunda, Cuarta, del Estatuto del Principado de Asturias y que pasa a la Ley 7/1985, de 2 de abril, de Bases de Régimen Local (LBRL, en adelante), no deja de presentar ciertos reparos, como en alguna ocasión la doctrina ha puesto de relieve ${ }^{17}$, ya que no se ha producido la transformación de la Entidad local provincial en Comunidad Autónoma - dando lugar a una entidad de naturaleza mixta de la que habla la doctrina antes citada-, sino la pura y simple desaparición de la primera, para dar paso a la existencia de una nueva y distinta entidad, sin que orgánica ni funcionalmente se mantengan las características de una Administración pública de carácter representativo como es lo propio de la Administración local, para encontrarnos con una Administración estrictamente burocrática, como son las Administraciones autonómicas, estructuradas a imagen y semejanza de la Administración estatal.

Con ello, indudablemente se produce un empobrecimiento de la vida local y de los principios de participación en que descansa el régimen local,

\footnotetext{
${ }^{15}$ La supresión de los órganos políticos de la Diputación provincial y la integración de su Administración en la de la Comunidad Autónoma, tal como se recoge en los Estatutos de las Autonomías uniprovinciales, fue resultado de los Acuerdos autonómicos suscritos por UCD y el PSOE en julio de 1981, desbloqueando el proceso, tomando como base el Informe de la Comisión de Expertos de mayo de 1981 y cuando ya se habían aprobado los Estatutos de Cataluña, País Vasco y Galicia.

${ }^{16}$ Con anterioridad el propio TC, en su sentencia 32/1981, de 28 de julio, había admitido que «una sola provincia se erija en Comunidad autónoma, asumiendo así un nivel superior de autonomía y estando en este caso confiado su gobierno y administración a la Comunidad»(FJ.3).

${ }^{17}$ Cfr. R. Entrena Cuesta, Curso de Derecho administrativo I-1 (Madrid 1998), pp. 37 ss. y «Concepto y estructura de la Administración pública en la Constitución», en Homenaje al Prof. Galván Escutia (Valencia 1978), pp. 147 ss; J. L. Martínez LóPEZ-MuñIZ, «Provincia-entidad local y Comunidades autónomas uniprovinciales», op. cit. in totum. Este último autor inicialmente había manifestado sus reservas desde el punto de vista constitucional a la fórmula utilizada por el Estatuto del Principado de Asturias en Estudios sobre el proyecto de Estatuto de autonomía para Asturias (Oviedo 1982), pp. 37-38.
} 
con consecuencias contrarias a los propios principios en que se fundamentan el Estado de las Autonomías. Baste como simple ejemplo de tal situación referirse al Plan de Cooperación de Obras y Servicios de competencia municipal, que es una de las principales funciones de las Diputaciones provinciales (art. $36 \mathrm{LBRL}$ ); asumida la competencia por la Comunidad Autónoma el Plan va a ser elaborado con criterios puramente tecnocráticos, sin mayor intervención de los Ayuntamientos de la provincia, mientras que cuando su aprobación corresponde a la Diputación, ésta, en cuanto órgano de gobierno de la provincia, se encuentra constituida por los concejales de los Ayuntamientos elegidos diputados provinciales por las correspondientes circunscripciones, respondiendo al carácter de Corporación interadministrativa territorial determinada por la agrupación de municipios. Algo análogo puede decirse en relación al Presupuesto y a los ingresos propios de las Diputaciones; la aprobación del Presupuesto de las entidades locales exige su exposición al público para reclamaciones (art. 150 Ley 39/1988, de Haciendas locales) y su posible impugnación por parte de los habitantes del territorio de la entidad, situación que no se da respecto del presupuesto de la Comunidad Autónoma.

Con ello, el principio recogido en la Ley del Proceso Autonómico estableciendo que «las Comunidades autónomas uniprovinciales, tendrán además el carácter de Corporación representativa, a que se refiere el art. 141.2 de la Constitución» (art. 9.2), se queda en una mera declaración puramente nominal, sin contenido real alguno, como consecuencia de la solución simplista a que se ha llegado en este punto. Con buen criterio la LBRL no reitera tal norma, por no responder a las características propias de las Comunidades Autónomas uniprovinciales. Por diversos motivos, no se ha querido o sabido encontrar una fórmula más plenamente constitucional que llevase a efecto la transformación de la entidad local provincial en Comunidad Autónoma, sin perder esas características orgánicas y funcionales que distinguen a la Provincia como entidad local y que le atribuye la Constitución.

\section{LEGISLACIÓN AUTONÓMICA DEL PRINCIPADO DE ASTURIAS SOBRE ADMINISTRACIÓN LOCAL}

A diferencia de otras Comunidades Autónomas el Principado de Asturias no cuenta con una ley general de Administración local que, en ejercicio de tal competencia, venga a desarrollar la legislación estatal de carácter básico ${ }^{18}$.

\footnotetext{
${ }^{18}$ Inicialmente fue Cataluña quien aprueba la Ley Municipal y de Régimen local 8/1987, de 15 de abril, objeto de diversas modificaciones posteriores. Una de las últimas leyes autonómicas de
} 
Únicamente ha aprobado leyes singulares en relación a determinados aspectos del régimen local, en virtud de las competencias que estatutariamente ha asumido.

Concretamente, han sido tres las leyes promulgadas hasta la fecha, referentes a Comarcas (Ley 3/1986, de 15 de mayo), Demarcación Territorial de Concejos (Ley 10/1986, de 7 de noviembre) y de la Parroquia Rural (Ley 11/1986, de de 20 de noviembre).

\section{Regulación de Comarcas}

La comarca como entidad local aparece reconocida en la norma estatutaria en cuanto institución que forma parte de la organización territorial del Principado de Asturias (art. 6.1. EA) y la competencia autonómica para su regulación se encuentra recogida en el artículo 10.1.2 ( creación de organizaciones de ámbito... superior» al municipio; inicialmente esta competencia se incluía en el art. 11 a. EA no como competencia exclusiva, sino como desarrollo de la legislación básica del Estado).

La Ley 7/1985, de 2 de abril, de Bases del Régimen local, reconoce a las Comunidades Autónomas esta competencia para «crear en su territorio comarcas $u$ otras entidades que agrupen varios municipios...» (art. 42.1.), estableciendo una serie de principios respecto a la iniciativa para su creación, organización y funcionamiento de sus órganos de gobierno y alcance de su competencia (art. 42, apartados 2, 3 y 4 que han sido declarados plenamente conformes al bloque de constitucionalidad) (STC 214/1989, FJ 13).

La aprobación de la Ley asturiana de Comarcas ha sido consecuencia del debate en el pleno de la Junta General del Principado sobre política territorial, que dio lugar a la resolución de 20 de junio de 1984 que instaba al Consejo de Gobierno a remitir a la Cámara un proyecto de ley regulando la organización comarcal, en línea con una posición que un tanto ingenuamente; - como ha denunciado Aurelio GuarTA-, considera a la

Régimen local es la de La Rioja (Ley 3/2003, de 3 de marzo). Otras Comunidades Autónomas que disponen de leyes de tal carácter son Galicia (Ley 5/1887, de 22 de julio), Murcia (Ley 6/1988, de 25 de agosto), Aragón (Ley 7/1999, de 9 de abril, modificada por Ley 15/1999, de 29 de diciembre), Castilla-La Mancha (Ley 3/1991, de 14 de marzo), Navarra (Ley 6/1990, de 22 de julio) y Castilla y León (Ley 1/1998, de 4 de junio). Canarias regula los Cabildos insulares y los Municipios en la Ley de Régimen Jurídico de las Administraciones públicas de 26 de julio de 1990 (Capítulos IV y V). 
comarca poco menos que la panacea para resolver los problemas de nuestras Administraciones locales ${ }^{19}$.

La Ley 3/1986, de Comarcas, aprobada cuando ya había sido promulgada la LBRL, presenta un carácter estrictamente procedimental, ya que la regulación de los contenidos referentes a la organización, funcionamiento y competencias de las entidades comárcales quedan remitidos a cada una de las leyes singulares de creación, aprobadas por la Junta General del Principado y que constituyen la norma básica de la institución (art. 3 Ley 3/1986).

De conformidad al carácter de la ley, que queda indicado, se regula la iniciativa para la creación de comarcas que se atribuye tanto a los Ayuntamientos como a los vecinos mediante petición a la Comunidad Autónoma y excepcionalmente a la propia Junta General del Principado, en sustitución de la iniciativa de las Corporaciones locales (art. 4 de la Ley). En todo caso, no podrá prosperar la iniciativa si a ello se oponen dos quintas partes de los Ayuntamientos que deban agruparse o cuando la oposición parta de los Concejos que representen al menos la mitad del censo electoral del territorio correspondiente (art. 5 de la Ley).

Trasladada la iniciativa al Consejo de Gobierno si éste la estima viable redactará el correspondiente anteproyecto de ley, que será sometido a información pública por plazo de dos meses para vecinos y Ayuntamientos afectados. Cuando el Consejo de Gobierno entienda inviable la creación lo pondrá en conocimiento de los promotores y de la Junta General, dando lugar al correspondiente debate, de conformidad al Reglamento de la Cámara, y si ésta se manifiesta favorable a su creación el Consejo de Gobierno quedará obligado a redactar el correspondiente proyecto de ley (art. 8 de la Ley).

El contenido preceptivo de la ley de creación de comarcas aparece recogido en el artículo 9 de la Ley: ámbito territorial, competencias, composición y funcionamiento de los órganos de gobierno, recursos, cabecera de comarca y sede de sus órganos.

Es de indicar que hasta la fecha no ha sido constituida ninguna comarca con el carácter de entidad local en el territorio asturiano, encontrándonos con el hecho de que la finalidad perseguida de contar con una organización adecuada para la prestación de servicios, en un ámbito territorial

\footnotetext{
${ }^{19}$ A. Guarta, «Competencia del Estado y las Comunidades Autónomas en materia de Régimen local», op. cit., pp. 375-276.
} 
superior al municipal, viene cubierta por la existencia de mancomunidades voluntarias de concejos de las que existe una amplia representación.

\section{Demarcación territorial de los Concejos}

Bajo esta denominación la Ley 10/1986, de 7 de noviembre, regula los diferentes procedimientos de alteración de los términos municipales, persiguiendo facilitar la constitución de entidades adecuadas a la mejor prestación de los servicios, que por exigencia legal deben cumplir las entidades municipales.

El ejercicio de la competencia autonómica para regular esta cuestión es consecuencia de la atribución que en favor de las Comunidades Autónomas se contiene en la norma constitucional (art. 148,1, 2. ${ }^{\mathrm{a}} \mathrm{CE}$ ), tal como reconoce la LBRL (art. 13) y se recoge en el artículo 10.1.2 EA de la Comunidad Autónoma del Principado de Asturias.

La Ley básica estatal después de reconocer la competencia autonómica para la creación y supresión de municipios, así como para la alteración de los términos municipales, simplemente determina que se requerirá «en todo caso audiencia de los municipios interesados y dictamen del Consejo de Estado o del órgano consultivo superior de los Consejos de Gobierno de las Comunidades autónomas, si existiere» (art. 13.1. LBRL). Condición necesaria para la creación de nuevos municipios habrá de ser la existencia de «núcleos de población territorialmente diferenciados y.... cuenten con recursos suficientes para el cumplimiento de las competencias municipales y no supongan disminución en la calidad de los servicios que venían siendo prestados» (art. 13.2. LBRL).

Los distintos supuestos o tipología de las alteraciones del término municipal se recogen en el artículo 2 de la Ley 10/1986 y son coincidentes con los que se regulan en el artículo 3 del Texto Refundido de las Disposiciones vigentes en materia de Régimen local (R.D. Legislativo 781/1986, de 18 de abril) (TRLRL, en adelante), aprobado en lo que a esta cuestión se refiere con carácter supletorio, en defecto de legislación autonómica (Disposición Adicional primera LBRL).

La legislación autonómica asturiana regula un procedimiento ordinario de alteración de términos municipales (art. 15), iniciado a petición del Concejo mediante acuerdo plenario aprobado con el voto favorable de las dos terceras partes del número de hecho y en todo caso de la mayoría absoluta legal de los miembros que integran la Corporación. Al lado de este 
procedimiento ordinario se contemplan en los artículos 16 y 17 otros procedimientos especiales en ausencia de iniciativa voluntaria municipal, iniciados de oficio por la Comunidad Autónoma, siempre y cuando concurran determinadas circunstancias (confusión de núcleos urbanos a consecuencia de la expansión urbanística; insuficiencia de recursos económicos; despoblación del concejo), o a petición de la mayoría de los vecinos de una zona determinada del municipio, ante la Consejería competente de la Comunidad Autónoma, pidiendo la segregación de la misma para incorporarse a otro municipio.

Por último, la Ley regula la alteración del nombre y capitalidad de los Concejos, reiterando la normativa que al efecto se contiene en el TRLRL (art. 11), así como las ayudas e incentivos por parte de la Administración autonómica en los supuestos de fusión o incorporación de concejos (art. 21).

\section{La Parroquia rural}

Ya quedó indicado en la Consideración previa que la existencia en Asturias de núcleos separados de población ha dado lugar, desde el punto de vista institucional, a la parroquia rural, reconocida como forma tradicional de convivencia y asentamiento poblacional (art. 6.2. EA). Se trata de una entidad infra-municipal cuya regulación corresponde a la legislación autonómica, tal como establece la LBRL (art. 45), dentro del marco que la ley básica estatal establece.

Por Ley 11/1986, de 20 de noviembre, el Principado de Asturias regula el reconocimiento de la Parroquia rural y la conversión de las entidades locales menores existentes en parroquias.

Se trata de una entidad local con personalidad jurídica para el cumplimiento de los fines que hayan determinado su constitución (art. 11, Ley 11/1986); estos fines vendrán dados por ser propios del grupo social asentado en un ámbito territorial determinado y separado del resto del Concejo y vinculados a la propiedad en mano común, a la gestión de servicios o a la ejecución de obras en las que predomine la aportación personal de los vecinos. En todo caso, es condición necesaria para su constitución que se trate de un núcleo rural que no sea capitalidad del concejo, ni se caracterice por una configuración típicamente urbana y sin que presente un predominio de sectores productivos distintos de aquellos que configuran y tipifican, sobre la base del cultivo de la tierra, el hábitat rural (arts. 2 y 3 de la Ley). 
Nos encontramos, por consiguiente, ante una entidad local menor de carácter netamente rural, por lo que puede entenderse que en el ámbito de la Comunidad Autónoma asturiana no cabe la constitución de una entidad local infra-municipal que no presente este carácter, como lo prueba que la ley prevé la conversión voluntaria de las entidades locales menores, legalmente constituidas, en Parroquias rurales (Disposición Transitoria Primera) y de no hacerlo así, trascurridos dos años, la Administración autonómica acordará su disolución o su sustitución por la Parroquia rural con exclusión del régimen de ayudas (Disposición Transitoria Segunda). Esta posición del ordenamiento autonómico del Principado de Asturias excluyendo la posibilidad de entidades locales menores de carácter netamente urbano, no parece muy conforme con el significado y alcance que debe ser reconocido a este tipo de entidades infra-municipales y sin que se justifiquen las posibles razones que han llevado a este posicionamiento legal.

El procedimiento para la constitución de Parroquia rural se acomoda a lo previsto en la LBRL y a la regulación que con carácter supletorio se contiene en el TRLRL (arts. 42 a 45). Se parte del principio de voluntariedad en la iniciativa (bien por la mayoría de los vecinos del correspondiente núcleo territorial o del Ayuntamiento a que éste pertenezca por acuerdo plenario adoptado por el voto favorable de dos tercios del número de hecho y en todo caso mayoría absoluta legal), aprobación por el Consejo de Gobierno por decreto previa información pública y traslado al Concejo para su pronunciamiento con el voto favorable de la mayoría absoluta legal (arts. 4 y ss. de la Ley).

Los órganos de gobierno y administración de la parroquia son los previstos en el artículo 45 2. b) LBRL y cuya elección se efectuará de conformidad al sistema electoral previsto en el artículo 199 de la Ley 5/1985, de 19 de junio, de Régimen Electoral General: un órgano unipersonal (Presidente), de elección directa por los vecinos de la parroquia y un órgano colegiado de control (Junta de Parroquia) formado por el Presidente y un número de miembros no inferior a dos ni superior al tercio de concejales del respectivo Concejo, cuya designación se efectúa de conformidad a los resultados de las elecciones para el Ayuntamiento en la Sección o Secciones constituidas en la circunscripción para la elección del órgano unipersonal (art. 14 Ley 11/1986) ${ }^{20}$.

\footnotetext{
${ }^{20}$ Como queda indicado, la ley autonómica se ajusta estrictamente a lo previsto en la LBRL, siendo de señalar que en esta cuestión (art. 45.2, b, LBRL) la ley estatal no tiene carácter básico, según. STC. 214/1989, por lo que no es vinculante para las Comunidades autónomas que quedan en libertad en este punto, ya que «se trata de una cuestión estrictamente organizativa que no presenta
} 


\section{TIPOLOGÍA DE LAS RELACIONES DE LAS ENTIDADES LOCALES CON LA COMUNIDAD AUTÓNOMA EN EL PRINCIPADO DE ASTURIAS}

Como no podía ser de otra forma, las relaciones de la Comunidad Autónoma con las entidades locales de su territorio discurren en el marco de las técnicas de relaciones interadministrativas arbitradas en la LBRL (Tít. V, Cap. II, arts. 55 ss.). Regulación que forma parte del bloque de constitucionalidad y que en cuanto tal ha de ser respetada por la legislación autonómica. Así lo viene entendiendo el TC al indicar que «el legislador autonómico no puede infringir los límites del control administrativo de los entes locales (establecidos en la legislación básica estatal), pues constituye un elemento esencial de dicha garantía constitucional» (STC 27/1987. FJ 9); y más específicamente al otorgarle a la LBRL en este punto el carácter «de función constitucional encomendada al legislador estatal de garantizar los mínimos competenciales que doten de contenido y efectividad a la garantía de la autonomía local» (STC 214/1989, FJ 3), «conteniendo los rasgos definidores de la autonomía local, concreción de los arts. 137, 140 y 141 de la CE» (STC de 5 de julio de 2001, FJ 4).

Tomando por base la autonomía de que gozan las entidades locales consagrada en el texto constitucional, nos encontramos con que estas relaciones interadministrativas cobran una especial fisonomía en el ordenamiento jurídico vigente, que las diferencian de forma substancial y no sólo nominal de las relaciones tradicionales Estado-Entidades locales. Por otra parte, al tratarse de un Estado compuesto como es el Estado de las Autonomías, con tres entidades territoriales dotadas de autonomía, estas relaciones interadministrativas adquieren una especial relevancia, debiendo responder a la configuración de tal tipo de Estado y a la posición constitucional de esos centros de referencia; por esta razón, al mismo tiempo, su formulación no deja de resentirse de la falta de un sistema constitucional preciso y bien definido de distribución competencia! entre las diferentes entidades que estructuran la organización territorial del poder.

Los principios a los que responden las relaciones interadministrativas se encuentran formulados con carácter general en el artículo 10.2 LBRL, estableciendo que «La Administración local y las demás Administraciones públicas ajustarán sus relaciones recíprocas a los deberes de información, colaboración, coordinación y respeto a los ámbitos competenciales res-

mayor incidencia en otros intereses generales de alcance supra autonómico, razón que impide calificar a las referidas previsiones como normas básicas» (FJ. 15). 
pectivos» ${ }^{21}$. Este precepto incluido en el Título I (Disposiciones Generales) de la LBRL encuentra su desarrollo en la propia ley, en el citado Capítulo II del Título V (arts. 55 a 62) ${ }^{22}$.

Esta regulación jurídico positiva de las relaciones interadministrativas que se contiene en la Ley 30/1992, de 26 de noviembre (LRJPAC), para las diferentes Administraciones públicas y en la LBRL para las relaciones en que sean parte las Entidades locales, es la lógica consecuencia de la estructuración del poder que diseña la $\mathrm{CE}$, descansando en última instancia en el principio de solidaridad en cuanto criterio fundamental de la vida social, recogido en el artículo 2 de la norma constitucional ${ }^{23}$. Así lo ha entendido el TC desde sus primeros pronunciamientos al considerar que el derecho a la autonomía «lleva como corolario la solidaridad entre todas ellas» (STC 25/1981, FJ. 3), por lo que la debida colaboración «no es menester justificar en preceptos concretos, se encuentra implícita en la propia esencia de la forma de organización territorial del Estado que implanta la Constitución» (STC 16/1992 FJ 14), ya que «la unidad del sistema en su conjunto, en el que las diferentes entidades autonómicas se integran, así como el principio de eficacia administrativa (art. 103.1 CE), que debe predicarse no solo de cada Administración pública sino del entero entramado de los servicios públicos, permiten, cuando no imponen, al legislador establecer fórmulas y cauces de relaciones entre unas y otras Administraciones locales y todas ellas con el Estado y las Comunidades autónomas en el ejercicio de las competencias que para la gestión de sus intereses respectivos les correspondan» (STC 27/198, FJ 2). Doctrina que se ratifica en la STC 214/1989, de 21 de diciembre, afirmando que al prin-

\footnotetext{
${ }^{21}$ Los mecanismos o técnicas jurídicas por medio de los que se llevan a cabo las informaciones reciprocas entre Administraciones públicas son muy variados, presentando un alcance diverso según nos encontremos ante relaciones de cooperación o de coordinación; Cfr. al respecto A. FroNTANA PUIG, «Las relaciones interadministrativas en la ley reguladora de las bases de régimen local», en REALA n. ${ }^{\circ} 235-236$, pp. 658-659.

${ }^{22}$ El art. 9 de la Ley 30/1992, de Régimen Jurídico de las Administraciones públicas y del Procedimiento administrativo común, establece que «las relaciones entre la Administración General del Estado o las Comunidades autónomas con las entidades que integran la Administración local se regirán por la legislación básica en materia de régimen local, aplicándose supletoriamente lo dispuesto en el presente título».

23 J. A. Santamaría Pastor, Fundamentos de Derecho administrativo I (Madrid 1988), pp. 272273 , considera que la solidaridad a que se refiere la norma constitucional presenta una triple vertiente: económica, exigencia de lealtad autonómica entre los diferentes entes territoriales y cooperación entre ellos para el ejercicio armónico y coordinado de sus respectivas competencias. Sobre el principio de solidaridad en la CE y sus posibles concepciones y diferencia de otros principios constituciones vid. P. Santolaya Machetti, Descentralización y cooperación (Madrid 1984), pp. 299 ss. Recientemente se ocupa de dicho principio, G. ReAL Ferrer, «La solidaridad en Derecho administrativo», en $R A P$ n. ${ }^{\circ} 161$, pp. 123 ss.
} 
cipio de colaboración «la propia estructura territorial aboca, ya que como ha señalado este Tribunal Constitucional en diversas ocasiones, la necesidad de hacer compatibles los principios de unidad y autonomía en que se apoya la organización territorial del Estado constitucionalmente establecida, implica la creación de instrumentos que permitan articular la actuación de las diversas Administraciones públicas» (STC 214/1989, FJ20.6.).

Como ha quedado indicado, la formulación de las relaciones interadministrativas en nuestro ordenamiento jurídico presenta la dificultad derivada de la ausencia de un modelo constitucional preciso y acabado de distribución del poder, dado que — por una parte - la configuración de las Comunidades Autónomas responde en el texto constitucional al denominado principio dispositivo y el modelo se resiente de la excesiva utilización del término competencia exclusiva, tanto en la Constitución como en los Estatutos de Autonomía, expresión a la que es preciso atribuir un sentido equívoco, como la jurisprudencia constitucional se ha visto obligada a precisar (SsTC de 16 de noviembre de 1981 (FJ. 1) y 5/1982, de 8 de febrero). Por otro lado, en lo que se refiere a los entes locales, la concreción de su autonomía queda diferida «al legislador ordinario, al que no se le fija más límites que el reducto indisponible o núcleo esencial que la Constitución garantiza» (STC 32/1981, FJ. 3), en cuanto que «la autonomía local es un concepto jurídico de contenido legal que permite, por tanto, configuraciones legales diversas» (STC 170/1989, FJ9).

Ello explica que el intérprete de la Constitución, inicialmente, se enfrente a la problemática de las relaciones interadministrativas de forma pragmática, sin responder a un sistema conceptual definido y con falta de precisión a la hora de utilizar las diferentes expresiones (colaboración, cooperación, coordinación) ${ }^{24}$. Así, en sus primeras sentencias, el TC plantea las relaciones interadministrativas en sentido fundamentalmente negativo (STC 4/1981, FJ 10), entendiendo que en el ejercicio de sus competencias los diferentes centros de poder han de abstenerse de lesionar los intereses del conjunto y de las demás organizaciones territoriales, por lo que «dado que cada organización territorial dotada de autonomía es una parte del todo, no cabe deducir de la Constitución que, en todo caso, corresponda a cada una de ellas un derecho o facultad que le permita ejercer las competencias que le son propias en régimen de estricta o absoluta separación» (STC 27/1987, FJ 2). Puede estimarse que fue a partir de

\footnotetext{
${ }^{24} \mathrm{Cfr}$. al respecto P. CRUZ Villalón, «La doctrina constitucional sobre el principio de cooperación», en Comunidades Autónomas e instrumentos de cooperación interterritorial (Madrid 1990), pp. 119 ss.
} 
la STC 227/1988, de 29 de noviembre, en relación con la Ley de Aguas y sobre todo de la STC 214/89, de 21 de diciembre, respecto de la LBRL, cuando el TC ha perfilado de forma más precisa y en sentido positivo las relaciones interadministrativas.

A partir de la doctrina constitucional ${ }^{25}$ y a la vista de la regulación jurídico-positiva contenida en la LBRL, las relaciones administrativas en que se puedan ver involucradas las entidades locales, prescindiendo de las relaciones de colisión ${ }^{26}$, pueden ser diferenciadas en relaciones de cooperación y relaciones de coordinación. El sentido y alcance de estas relaciones debe ser precisado tomando por base la doctrina constitucional que queda indicada y muy especialmente la contenida en la STC 214/1989 al enjuiciar la constitucionalidad de los artículos 58 a 62 LBRL.

Cooperación y coordinación son para el TC técnicas que se «orientan a flexibilizar y prevenir disfunciones derivadas del propio sistema de distribución de competencias, aunque sin alterar en ningún caso la titularidad y el ejercicio de las competencias propias de los entes en relación» ${ }^{27}$. Para

${ }^{25}$ Una exposición de la jurisprudencia constitucional en A. DE MARCO, «Jurisprudencia constitu-
cional sobre el principio de cooperación», en Documentación Administrativa n. ${ }^{\circ}$ 240, pp. $265 \mathrm{ss}$.

${ }^{26}$ Las relaciones de conflicto se encuentran reguladas en el Capítulo III, del Título V LBRL (arts. 63-68), que viene a judicializar plenamente este tipo de relaciones. En tal sentido las entidades locales podrán impugnar en vía contencioso-administrativa las disposiciones y actuaciones de las Administraciones estatal y autonómica (art. 63.2) y éstas, a su vez, solo podrán ir contra la actuación de los entes locales por vía judicial (arts 65 y 66). Únicamente en el supuesto de «actos $o$ acuerdos que atenten gravemente el interés general de España el Presidente del Gobierno.....podrá suspenderlos e impugnarlos seguidamente ante la jurisdicción contenciosoadministrativa» (art. 67 LBRL). Aparte de esta regulación de la LBRL, la Ley 7/1999, de 21 de abril, en aplicación del llamado Pacto local, ha venido a introducir un Capítulo V, en el Título IV de la Ley del TC, regulando el Conflicto constitucional en defensa de la autonomía local, persiguiendo superar la limitación que supone para las entidades locales el no estar legitimadas para accionar directamente ante el TC contra normas con fuerza de ley que entiendan atenían a su autonomía (Cfr. J. GonzÁlez Pérez, «Las entidades locales ante el proceso constitucional» en Homenaje a C. Ruiz del Castillo, Madrid 1985, pp. 239 ss.). No obstante, es preciso indicar que en la práctica se trata de un resquicio de muy escaso alcance, dados los condicionamientos que establece su regulación, al negar legitimación singular a los municipios y provincias, salvo en el supuesto de leyes singulares, para reconocer únicamente una legitimación selectiva sumamente restringida (art. 75 ter LO. 2/1979). Por consiguiente, las entidades locales aisladamente tendrán que seguir contentándose con acudir a la vía indirecta de la cuestión de inconstitucionalidad (art. 5 LO 6/1985, del Poder Judicial y arts. 35 ss LO 2/1979 del TC. al recurrir ante la Jurisdicción Contencioso-administrativa las actuaciones en aplicación de la disposición con fuerza de ley que consideren inconstitucional, sino es que se limitan a solicitar de la Comisión Nacional de Administración local que se dirija a los órganos constitucionalmente legitimados para que interpongan recurso directo de inconstitucionalidad (art. 119 LBRL).

${ }^{27}$ El TC había ya declarado en sus SsTC 27/1987 y 227/1988, en relación a la facultad estatal de coordinación, «que no supone, sin embargo, una sustracción o menoscabo de las competencias de 
esta doctrina constitucional las consecuencias y efectos de estas diferentes relaciones no son equiparables: la cooperación se caracteriza por la voluntariedad «frente a la imposición en la coordinación ya que toda coordinación conlleva un cierto poder de dirección, consecuencia de la situación de superioridad en que se encuentra el que coordina en relación con el coordinado» (STC 214/89, FJ. 20 f.) ${ }^{28}$. Por ello, en cierta forma, puede entenderse que la coordinación viene a cumplir en el Estado autonómico el papel de las técnicas de tutela y control del Estado unitario y centralista ${ }^{29}$.

\section{Manifestaciones de relaciones de cooperación}

El alcance jurídico que presenta este tipo de relaciones interadministrativas permite que la regulación de sus manifestaciones concretas pueda venir determinada por normas reglamentarias o surgir de meros convenios entre las Administraciones públicas afectadas, a diferencia de las relaciones de coordinación que, según veremos, deben encontrar su respaldo en normas con fuerza de ley.

Con carácter general es preciso señalar que este tipo de relaciones de colaboración voluntaria, mediante la cooperación y asistencia jurídica, económica y técnica de la Administración autonómica a las entidades municipales, cobran una especial significación e importancia en el Princi-

las entidades sometidas a la misma; antes bien presupone, lógicamente, la titularidad de las competencias en favor de la entidad coordinada» (STC 27/1987, FJ 2).

Un intento doctrinal de distinción entre cooperación y coordinación como técnicas interadministrativas en el plano de las relaciones Estado-Comunidades Autónomas, puede verse en P. SANTOLaya Machetti, Descentralización y cooperación, op. cit., pp. 33 ss. y 289 ss., especialmente.

${ }^{28}$ Esta forma de entender los diferentes supuestos de relaciones interadministrativas por parte del TC ha sido recogida y aplicada por el TS respecto de las relaciones provincia-municipio; así, en sus SSTS (Sala 3. ${ }^{a}$ ) de 18 de julio de 1987 y 3 de abril de 1998.

\footnotetext{
${ }^{29}$ Ello es lo que conduce a algún autor a considerar que la regulación de las relaciones interadministrativas de la LBRL está dando "paso a técnicas de control y tutela»; vid. en este sentido J. L. RIVERO YSERN, «Fórmulas administrativas de cooperación intermunicipal», en Rev. de Estudios de la Administración Local y Autonómica n. ${ }^{\circ} 228$, p. 672. En análogo sentido A. FANLo LorAs, «Relaciones de cooperación y nuevas tutelas», en Anuario de Gobierno Local 1997, pp. 153 ss., mantiene que en no pocas ocasiones la discrecionalidad, cuando no la arbitrariedad en la prestación de la cooperación a los municipios, al margen de una regulación material substantiva, para depender del más puro voluntarismo político, permite que nos encontremos ante una nueva tutela. También L. Morell, «La coordinación del Estado y las Comunidades autónomas con la Administración local», en Documentación Administrativa n. ${ }^{\circ} 230-231$, p. 110, no duda en considerar que la coordinación es «heredera a beneficio de inventario, claro está, de las anteriores figuras de la jerarquía y tutela».
} 
pado de Asturias al tratarse de una Comunidad Autónoma uniprovincial, que ha asumido las competencias propias de la Diputación provincial, por lo que le corresponde "garantizar los principios de solidaridad y equilibrio intermunicipal... y en particular asegurar la prestación integral y adecuada en la totalidad del territorio provincial de los servicios de competencia municipal» (art. $31 \mathrm{LBRL}$ ). Al efecto, las correspondientes atribuciones están conferidas a la Consejería de la Presidencia (Dirección General de Administración local, estructurada en el Servicio de Relaciones con las entidades locales y el Servicio de Cooperación y Desarrollo local) (art. 7, Decreto 83/2003, de 24 de julio, de Estructura básica de la Consejería de la Presidencia).

\subsection{Cooperación a obras y servicios de competencia municipal}

Una primera manifestación de estas relaciones de cooperación la encontramos en el Plan de Cooperación a Obras y Servicios de competencia municipal, llevado a efecto por la Comunidad Autónoma en ejercicio de las competencias asumidas de la Diputación provincial (art. 36.2 LBRL). Su aprobación, como ya quedó indicado, obedece a criterios puramente tecnocráticos, sin mayor participación de las entidades municipales afectadas, pudiendo encontrarnos con manifestaciones de puro clientelismo político. La elaboración, gestión y seguimiento del Plan de Cooperación corresponde al Servicio de Cooperación y Desarrollo Local (art. 9 D. 83/2003, de 24 de julio, de Estructuración orgánica básica de la Consejería de la Presidencia).

Esta manifestación de cooperación infra-provincial resulta «la forma tradicional y más importante de cooperación de las Diputaciones a las obras y servicios de competencia municipal», tal como ha sido calificada por la jurisprudencia (STS — Sala 32- de 3 de abril de 1998) ${ }^{30}$.

En relación a dicho Plan y para facilitar la aportación económica municipal el Principado de Asturias cuenta con la Caja de Crédito de Cooperación local, procedente de la extinguida Diputación provincial, como ente descentralizado dotado de personalidad jurídica, con la finalidad de conceder prestamos a las entidades locales para su aportación a las obras y servicios obligatorios incluidos en los Planes de Cooperación; la regulación de la Caja de Crédito de Cooperación se efectúa por D. 62/1992, de 16 de julio, con las modificaciones de los DD. 168/1995, de 14 de septiembre y 70/1996, de 14 de noviembre, que aprueba el Reglamento con-

\footnotetext{
30 De interés acerca de la competencia provincial en relación al Plan de Cooperación a las Obras y Servicios municipales la STS (Sala 3. ${ }^{\text {a }}$ ) de 27 de junio de 2003.
} 
teniendo la normativa referente a su organización, funcionamiento y régimen jurídico del contrato de préstamo ${ }^{31}$.

\subsection{Comisión Asturiana de Administración local}

Como órgano específico de colaboración entre la Administración del Principado de Asturias y los Concejos y demás entidades locales radicadas en su ámbito territorial la Ley $1 / 2000$, de 20 de junio, crea la Comisión Asturiana de Administración local.

De conformidad a lo previsto en el artículo 58 LBRL, la Comisión tiene un carácter meramente consultivo y asesor acerca de «cuantos asuntos derivados de las relaciones interadministrativas fuera interesada su opinión por la Administración afectada» (art. 1.2 de la Ley). La Comisión presenta una composición paritaria, estando presidida por el titular de la Consejería con competencia general en materia de cooperación local ${ }^{32}$.

\subsection{Sociedad de Servicios del Principado de Asturias S.A.}

Se encuentra autorizada su creación por Ley 7/2002, de 24 de junio, como empresa pública bajo la forma jurídica de sociedad anónima con capital íntegramente suscrito por la Administración autonómica. Le corresponde, entre otras finalidades, suscribir convenios de colaboración con las entidades locales del territorio asturiano, persiguiendo la realización de actividades de distinto tipo, tales como obras de construcción e infraestructura, realización de actuaciones y prestación de servicios de desarrollo rural, de interés agrario, de agricultura y pesca marítima, de interés medioambiental, turístico, docente, cultural y deportivo ${ }^{33}$.

\footnotetext{
${ }^{31} \mathrm{El}$ art. 10 del D. 83/2003 de 24 de julio, de Estructura básica de la Consejería de la Presidencia, al regular la Caja de Crédito de Cooperación local circunscribe la concesión de prestamos a las entidades locales con población igual o inferior a 40.000 habitantes, para facilitar la mejora de obras y servicios municipales y para favorecer la situación de las haciendas locales.

${ }^{32}$ La composición de la Comisión viene establecida por el art. 5.3 de la Ley, de la forma siguiente: 11 representantes de la Administración del Principado de Asturias; el Presidente de la Federación Asturiana de Concejos: el Director General competente en materia de cooperación local; los Alcaldes de los Concejos de población superior a 40.000 habitantes; un Alcalde por cada una de las tres circunscripciones electoras; un Alcalde en representación de los Concejos con población inferior a 2.000 habitantes; un Alcalde en representación de los Concejos con población comprendida entre 2.000 y 5.000 habitantes y un Alcalde en representación de los Concejos con población superior a 5.000 habitantes e inferior a 40.000 .

${ }^{33} \mathrm{El}$ art. 3 de la ley que autoriza su creación, precisa el objeto social.
} 


\subsection{Red asturiana de Desarrollo local}

Se encuentra regulada por D. 36/1994, de 5 de mayo, con objeto de lograr la integración de las Agencias de Desarrollo local promovidas por los Ayuntamientos y Mancomunidades municipales, que «teniendo por objeto la asistencia técnica en materia de formación ocupacional y fomento del empleo y el impulso de iniciativas locales de empleo... suscriban el oportuno convenio de colaboración con el Principado de Asturias» (art. 2 D. 36/1994). Los convenios suscritos determinarán el contenido y alcance de las ayudas y aportaciones a prestar por la Administración autonómica (art. 6 D. 36/1994).

\subsection{Asistencia letrada a los municipios}

Este tipo de colaboración se encontraba contemplada inicialmente en el D. $99 / 1988$, de 29 de septiembre y en la actualidad aparece regulada por el D. 20/1997, de 20 de marzo, de organización y funcionamiento del Servicio Jurídico del Principado de Asturias, cuyo Título III (arts. 31-29) está dedicado a la Defensa de las Entidades locales, estableciendo los supuestos, condiciones y forma de llevar a efecto la asistencia jurídica.

En principio, la asistencia letrada en defensa de los acuerdos emanados de los órganos de gobierno y administración de las entidades locales, así como de sus bienes y derechos, corresponde a la propia entidad, pudiendo celebrar convenios de colaboración con la Administración estatal para que sean los Abogados del Estado quienes les representen, defiendan y asesoren (art. 1 Ley 52/1997, de 27 de noviembre, de Asistencia Jurídica al Estado e Instituciones públicas) o bien con las Comunidades Autónomas ${ }^{34}$.

$\mathrm{Al}$ respecto, la LBRL recoge entre las competencias de las Diputaciones provinciales «la asistencia y cooperación jurídica... a los municipios, especialmente los de menor capacidad económica y de gestión» (art. 36.1.b.); en ejercicio de esta atribución el Principado de Asturias, en cuan-

\footnotetext{
${ }^{34}$ Es ello consecuencia de la modificación que introduce la L.O. del Poder Judicial de 1985, al señalar su art. 447.2 que «la representación y defensa de los entes locales corresponde a los letrados que sirvan en los servicios jurídicos de dichas Administraciones públicas, salvo que designen Abogado colegiado que les representen y defiendan», aclarando lo dispuesto al efecto en el art. 38.1. de la ley de la Jurisdicción Contencioso-administrativa de 1956, que atribuía dicha representación y defensa a los Abogados del Estado, salvo que las entidades locales «designen Letrado o litiguen entre sí o contra la Administración del Estado o con otras Corporaciones o instituciones públicas».
} 
to Comunidad Autónoma uniprovincial, debe llevar a cabo el asesoramiento y defensa jurídica de los Concejos de su territorio ${ }^{35}$.

El Decreto regulador del Servicio Jurídico del Principado de Asturias establece la asistencia letrada en favor de los concejos, comarcas, agrupaciones, mancomunidades y parroquias rurales con exclusión de los municipios con población superior a 20.000 habitantes o que cuenten en sus plantillas de personal con Abogado consistorial o similar (art. 31.3.). La asistencia será solicitada por el Alcalde o Presidente de la entidad, siendo acordada por el titular de la Consejería competente, previo informe del Servicio Jurídico a cuyos letrados corresponde la prestación de la asistencia (arts. 34 a 36 D. 20/1997, de 20 de marzo) ${ }^{36}$.

\subsection{Convenios de colaboración y entidades consorciales}

Práctica habitual es la realización de convenios de colaboración entre la Administración autonómica y los concejos asturianos sobre las más diversas materias, como manifestación de la autonomía que constitucionalmente tienen reconocida. El contenido y alcance de este tipo de relaciones interadministrativas pueden ser muy diversos, en cuanto expresión de la asistencia económica, técnica y jurídica del Principado da Asturias hacia los Concejos; desde la simple ayuda económica de carácter subvencional, hasta la creación de estructuras orgánicas, dando lugar a entidades de carácter mixto, entre las que destacan el consorcio, en cuanto entidad interadministrativa voluntariamente constituida e integrada por corporaciones municipales y otras entidades públicas de diferente orden ${ }^{37}$. A este tipo de entidades se refiere el artículo 6.5 LRJPAC y en el ordenamiento local los

\footnotetext{
${ }^{35}$ Así lo justifica el D. 99/1988 que inicialmente aprobó la asistencia letrada a las entidades locales por parte de la Comunidad Autónoma asturiana.

${ }^{36}$ Quedan excluidas: a) El ejercicio de acciones judiciales contra el Principado de Asturias, sus organismos autónomos y demás entes públicos y empresas dependientes: b) El ejercicio de acciones en que la entidad local mantenga posturas divergentes o contrarias a los intereses de la Administración del Principado de Asturias; c) Los procesos incoados a instancia de la Administración del Principado de Asturias o del Estado, en impugnación de actos y acuerdos municipales: d) La impugnación de actos y acuerdos locales por parte de los miembros de las Corporaciones respectivas; e) Las cuestiones penales en que sean parte las autoridades y el personal de las entidades locales; f) El ejercicio de acciones judiciales de cualquier clase contra otras entidades locales radicadas en el ámbito del Principado de Asturias o los organismos autónomos o de empresas de ellos dependientes; g) El ejercicio de acciones judiciales de cualquier clase contra la Administración del Estado; h) El ejercicio de acciones de carácter temerario, manifiestamente infundadas o contrarias al ordenamiento jurídico.
}

${ }^{37}$ Cfr. J. L. Martínez LóPeZ-Mũ̃̃z, Los consorcios en el Derecho español (Madrid 1954). 
artículos 57 y 87 LBRL. La fórmula venía siendo ya utilizada por la extinguida Diputación provincial asturiana con los Ayuntamientos, al amparo de lo dispuesto en el artículo 37 del Reglamento de Servicios de las Corporaciones locales de 1955 y continúa haciendo uso de la misma la Comunidad Autónoma. Ejemplos importantes son el Consorcio para el Abastecimiento y Saneamiento de la Zona Central de Asturias (CADASA), el Consorcio para la Gestión de Residuos Sólidos (COGERSA) y el Consorcio de Extinción de Incendios, Salvamento y Protección civil (CEISPA).

\subsection{Delegación intersubjetiva de competencias}

Entre las técnicas funcionales de colaboración hay que contar con la delegación inter-subjetiva de competencias que, ciertamente, adquiere un especial significado e importancia en todo Estado compuesto ${ }^{38}$. Así se encuentra expresamente previsto en nuestra Constitución, respecto de las relaciones Estado-Comunidades Autónomas, al establecer su artículo 150.2 la posibilidad de delegar «mediante ley orgánica facultades correspondientes a materia de titularidad estatal», y la LBRL distingue las competencias propias, de las atribuidas por delegación (art. 7.1.), dado que el artículo 27 establece que «la Administración del Estado, de las Comunidades autónomas y de otras Entidades locales podrán delegar en los Municipios el ejercicio de competencias en materias que afecten a sus intereses propios, siempre que con ello se mejore la eficacia de la gestión pública y se alcance una mayor participación ciudadana» ${ }^{39}$.

Todos los Estatutos de Autonomía contemplan este tipo de relaciones interadministrativas con mayor o menor énfasis; así se recoge en el artículo 24.6 del Estatuto de Autonomía del Principado de Asturias, al incluir entre las competencias de la Junta General el «regular la delegación de competencias administrativas del Principado en uno o varios municipios o en las organizaciones territoriales a que hace referencia el artículo 6» (Comarcas, Parroquias rurales y Áreas metropolitanas).

Supuesto significativo de esta relación interadministrativa de transferencia de competencia se encuentra en la Ley 12/1984, de 21 de noviembre, que autoriza al Consejo de Gobierno del Principado de Asturias a delegar en los Ayuntamientos determinadas facultades previstas en el

\footnotetext{
${ }^{38}$ Cfr. L. Morell Ocaña, La delegación entre entes en el Derecho público español (Madrid 1972), aunque se trata de un estudio anterior al ordenamiento constitucional vigente.

${ }^{39}$ El TRLRL, aprobado por Decreto legislativo 781/1986, regula esta transferencia de competencias en sus arts. 66-68.
} 
Reglamento de Actividades Molestas, Insalubres, Nocivas y Peligrosas, que habían sido transferidas por el Estado en virtud del R.D. 2874/1979, de 17 de diciembre, en materia medioambiental. La delegación se efectuará a petición del Concejo interesado o por iniciativa de la Administración autonómica, previa aceptación del municipio, siempre y cuando que el ente delegado cuente con Oficina o Servicio técnico que asegure una eficaz gestión, bien directamente o sostenida en régimen de mancomunidad o agrupación (art. 2.1. Ley 12/1984).

Recientemente la Ley 3/2002, de 19 de abril, de Régimen del Suelo y Ordenación urbana, estableció la delegación ex lege en favor de los municipios de más de 40.000 habitantes, para la aprobación definitiva de los Planes Generales de Ordenación urbana (art. 9.1.), así como la posibilidad de delegación de dicha aprobación en concejos menores de esa cifra de habitantes, cuando cuenten con medios técnicos, jurídicos y administrativos adecuados (art. 9.2).

Se trata de una fórmula tomada de la Ley 7/1995, de 29 de junio, de la Comunidad Autónoma de Galicia, que «considerando la dimensión del urbanismo como consubstancial a la esfera local aconseja establecer las bases que jurídicamente hagan viable que la actuación autonómica en los municipios pueda tener lugar a través de la propia Administración municipal»; para ello se establece que «la competencia para la aprobación definitiva de los proyectos, planes, normas o programas de ámbito municipal que la legislación urbanística vigente atribuye a la Comunidad autónoma de Galicia queda asignada en régimen de competencia delegada a los municipios respectivos». Sin embargo, dado el sentido y alcance que presenta la facultad de control que es propia de las Comunidades Autónomas para la aprobación de los instrumentos de planificación urbanística, la delegación de dicha competencia en los municipios afectados no deja de presentar ciertas objeciones desde el punto de vista de estricta técnica jurídica ${ }^{40}$, ya que el verdadero sentido de la delegación inter-subjetiva de competencias la hace aplicable respecto de servicios y funciones materiales de titularidad del ente delegante, pero no para el supuesto de competencias formales de fiscalización o control sobre el ente delegado. Por ello, si políticamente puede reputarse oportuno dar una mayor intervención al propio municipios a la hora de aprobar su Plan General de Ordenación Urbana, desde el punto de vista jurídico otra debería ser la fórmula arbitrada.

\footnotetext{
${ }^{40}$ Cfr. J. L. DE LA VALLINA, «Autonomía local y aprobación por delegación de los planes generales de urbanismo», en Revista de Estudios de la Administración Local y Autonómica, n. ${ }^{\circ}$ 268, pp. 11 ss.
} 


\subsection{Colaboración en el ámbito urbanístico}

Un ámbito en el que se hace especialmente intensa las relaciones de colaboración entre el Principado de Asturias y los concejos de su territorio es el urbanismo. La Ley urbanística del Principado de Asturias de 19 de abril de 2002 plantea la debida colaboración entre las Administraciones públicas competentes en su artículo 11 bajo «los principios de cooperación, asistencia activa e información recíproca», en cuanto presupuesto necesario del sistema de distribución competencial propio de un Estado compuesto como es nuestro Estado de las Autonomías, tal como viene señalando la doctrina constitucional desde sus primeros pronunciamientos (SSTC 18/1982; 64/1982 y 76/1983). Específicamente, el n. 2 de dicho precepto legal prevé el «apoyo y asistencia técnica» por parte del Principado de Asturias a las Entidades y gerencias urbanísticas municipales que lo precisen.

\section{Relaciones de coordinación}

Este tipo de relaciones se enmarcan con el significado y alcance que con carácter básico establece el artículo 59 LBRL, tal como ha sido precisado por la doctrina constitucional, sobre todo a partir de la STC 27/1987, de 27 de febrero, en la que se declara que la coordinación supone un «límite al pleno ejercicio de las competencias propias de las Corporaciones locales y como tal, en cuanto que afecta el alcance de la autonomía constitucionalmente garantizada, solo puede producirse en los casos y con las condiciones previstas en la ley» (STC 27/1987, FJ. 2).

La coordinación como principio que ha de presidir el ejercicio de las competencias de las Administraciones públicas se encuentra recogido en el texto constitucional (art. 103 1.CE.) y es exigencia derivada de la eficacia y coherencia en la consecución de los intereses generales que debe perseguir la actuación administrativa.

El presupuesto fáctico para que pueda proceder es que las competencias de las entidades locales objeto de coordinación «trasciendan el interés propio de las correspondientes entidades, incidan o condicionen relevantemente los de... (otras) Administraciones o sean concurrentes o complementarias con los de éstas» (art. 10.2. LBRL) ${ }^{41}$. En todo caso la coordi-

\footnotetext{
${ }^{41}$ Sobre los diversos supuestos de hecho en que puede proceder la coordinación, vid. L. MoReLL. «La coordinación del Estado y las Comunidades autónomas con la Administración local», op. cit., p. 113 ss.
} 
nación por parte de la Comunidad Autónoma, sobre competencias y servicios propios de los municipios, exigirá que los fines que con ella se persigan no puedan ser logrados por medio de otros procedimientos menos restrictivos de la autonomía local, como son los que se manifiestan a través de las relaciones de cooperación. En tal sentido, la coordinación aparece con carácter subsidiario respecto de otras posibles técnicas de relaciones interadministrativas más respetuosas con la autonomía municipal, tal como se desprende de la regulación que se contiene en el citado artículo 59.1 LBRL.

La coordinación en cuanto que entraña una facultad de dirección, que expresa una cierta superioridad, se manifiesta fundamentalmente en planes sectoriales, a los que se refiere la LBRL en su artículo 59.1, párrafo segundo, y en directrices de actuación que condicionan la competencia del ente coordinado ${ }^{42}$, aparte de la posible creación de órganos mixtos de colaboración que persigan como resultado la debida coordinación por medio de la deliberación o consulta y desprovistos de facultades decisorias (art. 58. 1 LBRL).

En ningún supuesto el condicionamiento de las competencias locales, en virtud de las facultades de coordinación que correspondan al Estado o a las Comunidades Autónomas, puede impedir la toma de las correspondientes decisiones por parte del ente objeto de la coordinación. Así se desprende de la doctrina constitucional al señalar que «la coordinación implica la fijación de sistemas de relación... evitando disfunciones que produciría la gestión separada de los servicios públicos con incidencia en diversos ámbitos de intereses relacionados entre sí. Pero no puede traducirse en órdenes concretas que prefiguren exhaustivamente el contenido de la actividad del ente coordinado, agotando su propio ámbito de decisión autónoma; en cualquier caso, los medios y técnicas de coordinación deben respetar un margen de libre decisión o de discrecionalidad en favor de las Administraciones sujetas a la misma»(STC 27/1987, FJ 6).

Por consiguiente, hay que entender que la coordinación opera en aquellos supuestos en que el ordenamiento jurídico garantiza el respeto a la voluntad del ente objeto de la coordinación, haciendo preciso acudir a esta técnica de relación interadministrativa porque ninguno de los sujetos afectados ostenta una superioridad suficiente para imponer su voluntad a los demás.

\footnotetext{
${ }^{42}$ A las directrices de actuación como técnica de coordinación se refiere L. MorelL, «La coordinación del Estado y las Comunidades autónomas con la Administración local», op. cit., pp. 126 ss., comentando la posición del TC acerca de tal técnica de coordinación (STC 27/1987, de 27 de febrero).
} 
Expresión de estas técnicas de coordinación en las relaciones del Principado de Asturias con los Concejos de su territorio la podemos encontrar en los supuestos reseñados seguidamente.

\subsection{La Ley 6/ 1988, de 5 de diciembre, de Coordinación de Policías locales}

Hace referencia a la competencia estatutariamente asumida por el Principado de Asturias para «la coordinación de las policías locales, sin perjuicio de su dependencia de las autoridades municipales» (art. $20.1 \mathrm{EA})$. La competencia autonómica para la coordinación en este campo se enmarca dentro de los términos previstos en la Ley Orgánica 2/1986, de 13 de mayo, de Cuerpos y Fuerzas de Seguridad del Estado, promulgada de conformidad a lo establecido en el artículo 149.1. 22 CE, tal como ha sido reconocido por el TC al conocer del recurso interpuesto contra la Ley autonómica asturiana 6/1988 (STC 50/1993 de 11 de febrero) ${ }^{43}$.

Como órgano para lograr la finalidad perseguida la Ley autonómica 6/1988 establece la «Comisión de coordinación de las Policías locales», cuyas facultades vienen especificadas en el artículo 6, debiendo entenderse que son meramente deliberativas y consultivas, dado el carácter que debe atribuirse a los órganos de coordinación, de conformidad a lo preceptuado en la Ley básica de régimen local (art. 58.1. LBRL).

La ley al referirse a las técnicas jurídicas para llevar a efecto la coordinación menciona las normas-marco y los criterios, que pueden incluirse dentro de lo que doctrinalmente se conoce bajo la denominación de directrices. Estas últimas son un procedimiento de coordinación que aunque no está incluido expresamente en el artículo 59 LBRL, que simplemente alude a los planes sectoriales, hay que considerarlas — como ya quedó indicado - como una de las técnicas que el legislador autonómico puede utilizar para llevar a cabo la coordinación, tal como reconoce el TC en el recurso de inconstitucionalidad contra la Ley de la Generalidad valenciana de 4 de octubre de 1983, que declara de interés general determinadas funciones de las Diputaciones provinciales (STC 27/1987). Se trata de un tipo de acto jurídico de contenido no siempre preciso, ya que puede amparar aspectos normativos o simples criterios

\footnotetext{
${ }^{43}$ La STC 50/1993 únicamente declara la inconstitucionalidad del apartado i) del art. 3.1., en cuanto hace referencia a la creación de Cuerpos de Policía supramunicipales, lo que no es conforme a lo preceptuado en la L.O. de Cuerpos y Fuerzas de Seguridad del Estado, en la que «no se contemplan otros Cuerpos de Policía local que los propios de los municipios (art. 11), de manera que todas las facultades de las Comunidades autónomas concernientes a estos Cuerpos... han de entenderse referidas solo a los de Policía municipal» (STC 50/1993, FJ 3).
} 
de actuación; no obstante, en puridad las directrices no son propiamente normas jurídicas, sino que vienen a interpretar y dar sentido al ordenamiento jurídico respecto de una situación fáctica concreta, estableciendo una previsión acerca de la conducta que debe seguirse. Todo ello hace que las directrices guarden una cierta semejanza con las instrucciones y circulares, en cuanto que persiguen finalidades análogas, aunque la diferencia hay que encontrarla en el distinto supuesto en que operan unas y otras: las instrucciones y circulares dentro de una relación jerárquica entre órganos de una misma persona jurídica y las directrices entre Administraciones públicas diferentes para la debida coordinación de sus respectivas competencias.

La fuerza jurídica o vinculación para los destinatarios de las directrices se encuentra no sólo en la norma que interpretan, sino también en la propia normativa que impone la coordinación, aunque dado el alcance que debe darse a este tipo de relaciones interadministrativas - tal como ha quedado precisado por la doctrina constitucional- el ente coordinador ha de permitir la actuación del ente coordinado, sin posible sustitución de su voluntad ni suspensión de su actuación. Así lo viene a reconocer la propia ley autonómica asturiana al determinar que «estas funciones de coordinación (de policías locales) se ejercerán en todo caso respetando la autonomía y las competencias de las autoridades locales en la materia» (art. 3.2 Ley 6/1988). Al respecto, hay que señalar que el incumplimiento de la directriz permitirá al ente coordinador la impugnación de la actuación del ente coordinado, en cuanto que pueda entrañar la vulneración de la norma objeto de interpretación, así como de la propia norma que ampara la coordinación. Es ésta la postura que se desprende de la doctrina constitucional contenida en la STC 27/1987, al entender que se infringe la autonomía local por atribuir a la Comunidad Autónoma la facultad de suspender los acuerdos adoptados por las Diputaciones provinciales contrarios a las directrices: "tras la aprobación de la Ley de bases de régimen local 7/1985, de 2 de abril, carece de legalidad la suspensión aparejada al requerimiento que el impugnado artículo 12, párrafo 2. ${ }^{\circ}$, de la Ley 2/1983, establece» (STC 27/1987, FJ 9.)

\subsection{Coordinación urbanística: la ordenación del territorio}

La expresión más significativa de la actividad autonómica coordinadora de las competencias municipales la encontramos en materia urbanística.

Indudablemente el núcleo central y básico del urbanismo hace referencia a potestades y atribuciones netamente municipales. Así lo tiene reco- 
nocido el TC al señalar que incide en «lo que podemos llamar políticas de ordenación de la ciudad, en tanto en cuanto mediante ellas se viene a determinar el cómo, cuándo y dónde deben surgir o desarrollarse los asentamientos humanos y a cuyo servicios se disponen las técnicas e instrumentos urbanísticos precisos para lograr tales objetivos» (STC 61/1997, FJ 6). Doctrina constitucional que no duda en afirmar que entre los diversos ámbitos que afectan a intereses locales se encuentra el urbanismo "como una de sus manifestaciones más importantes... entre los asuntos de interés de los municipios y a los que por tanto se extienden sus competencias está el urbanismo» (STC 40/1998, FJ 29). Por otra parte, y como no podía ser de otra forma, la LBRL así lo recoge en su artículo 25.2 con el carácter y significado que este texto legal presenta en nuestro ordenamiento jurídico.

Ahora bien, esta competencia municipal referente al urbanismo de su término ha de ser coordinada con actuaciones de otras Administraciones públicas sobre ese mismo espacio territorial, por razones de eficacia administrativa, coherencia y unidad del sistema administrativo en su conjunto. Esta coordinación puede considerarse que es el contenido básico de la ordenación del territorio como competencia que atribuye a las Comunidades Autónomas el texto constitucional (art. 148.1.3). Ciertamente, la ordenación del territorio no presenta doctrinalmente un contenido preciso, tratándose de un concepto un tanto vago e impreciso, susceptible de enfoques diversos, dando lugar a modelos diferentes de ordenación territorial; falta de concreción que en cierta forma viene reconocida por nuestro TC al indicar que «sobre el concepto mismo de ordenación territorial son escasas las precisiones que se encuentran en nuestra doctrina» (STC 149/1991, FJ 1.B), para afirmar — recogiendo pronunciamientos anteriores- que «tiene por objeto la actividad consistente en la delimitación de los diversos usos a que puede destinarse el suelo o espacio físico territorial» (STC 77/1984, FJ 2) y cuyo núcleo fundamental «está constituido por un conjunto de actuaciones públicas de contenido planificador cuyo objeto consiste en la fijación de los usos del suelo y el equilibrio de las distintas partes del territorio» (SsTC 36/1994, FJ 3, 28/1997, FJ 5 y 144/1998, FJ 3). Por ello, la ordenación del territorio ofrece una visión más amplia que la estrictamente urbanística, en cuanto que persigue integrar diferentes perspectivas relevantes desde distintos puntos de vista: social, económico, cultural, ecológico... tal como queda reflejado en la Carta Europea de Ordenación del Territorio de 1983.

Vigente la Constitución y constituidas las Comunidades Autónomas prácticamente todas ellas han ido aprobando leyes de Ordenación del 
Territorio y Directrices Territoriales, que vienen a coordinar la actividad urbanística municipal ${ }^{44}$.

El Principado de Asturias, después de los RR.DD. 3392/1983 y 3511/1983, de Traspasos de funciones y servicios del Estado en materia de ordenación de las zonas costeras y vertidos al mar y de estudios de ordenación del territorio y medio ambiente, respectivamente, va a asumir de forma plena la competencia coordinadora por medio de la Ley 1/1997, de 30 de marzo, de Coordinación y Ordenación Territorial, objeto de modificación parcial por la Ley 3/2002, de 19 de abril, de Régimen del Suelo y Ordenación urbana, en virtud de los dispuesto en su Disposición Adicional Primera. A esta coordinación de la actividad urbanística se refiere el artículo 12 de la Ley 3/2002, al establecer que las competencias en este ámbito «se ejercerán en coordinación con las atribuidas por la ley para la gestión de otros intereses públicos específicos cuya realización requiera ocupar o transformar el territorio y afectar el régimen de utilización del suelo», remitiendo al efecto a lo previsto en la Ley 1/1997, de Coordinación y Ordenación Territorial.

La Ley de Coordinación y Ordenación Territorial va a regular los típicos instrumentos propios de la actividad coordinadora, es decir, los planes sectoriales a los que expresamente se refiere el artículo 59 LBRL y las directrices. En efecto, la Ley autonómica 1/1997 para lograr racionalizar y coordinar la actuación administrativa desde una óptica territorial va a utilizar un conjunto de instrumentos bajo la denominación de Directrices de Ordenación Territorial. Programas de Actuación y Evaluación de Impacto Ambiental y Estructural, a los que se añaden los Planes Territoriales Especiales Supramunicipales (en virtud de la Disposición Adicional Primera de la Ley 3/2002); con ello se dispone de instrumentos precisos para la coordinación en todas las fases del proceso: desde la planificación, ya sea estrictamente municipal (Directrices) o supramunicipal (Planes Especiales), hasta la ejecución material (Evaluación de Impactos), pasando por la programación

\footnotetext{
${ }^{44}$ Inició el proceso Cataluña con la Ley 23/1983, de 21 de noviembre, de Política Territorial, regulación que se mantiene en la Ley de Urbanismo de Cataluña de 14 de marzo de 2002, cuyo art. 5 establece que el urbanismo ha de ajustarse a los planes territoriales y aplicar en todo caso las directrices del Plan Territorial General. Modelo diferente de ordenación territorial lo ofrece la Ley de la Comunidad de Madrid de 20 de mayo de 1984, que regula una serie de instrumentos de planeamiento de distinto alcance y configuración, no jerarquizados entre sí. Estos modelos son los que vienen inspirando la legislación autonómica en la materia: Andalucía (Ley 1/1994, de 11 de enero); Aragón (Ley 11/1992, de 24 de noviembre); Canarias (Ley 9/1999, de 13 de mayo); Cantabria (Ley 7/1990, de 30 de marzo); Castilla y León (Ley 10/1995, de 5 de diciembre); Galicia (Ley 10/1995, de 23 de noviembre); Murcia (Ley 4/1992, de 30 de julio); La Rioja (Ley 20/1998, de 29 de junio).
} 
(Programas de Actuación que especifiquen los costes y plazos de las ejecuciones concretas a realizar por los diversos organismos y entidades).

Finalidad de esta coordinación urbanística será que la actuación municipal, empezando por la elaboración de los planes, quede vinculada por las determinaciones contenidas en los diferentes instrumentos de ordenación territorial, tal como expresamente señala el artículo 43 de la Ley de Régimen del Suelo y Ordenación urbanística de 19 de abril de 2002.

\section{Relaciones en orden a la iniciativa legislativa municipal respecto de competencias autonómicas}

Un ámbito relacional peculiar es el que se deriva del reconocimiento en favor de los concejos asturianos para promover iniciativas legislativas, en relación a las competencias exclusivas del Principado de Asturias (art. 31 EA). Se trata de una potestad reconocida a los Ayuntamientos que está recogida en algunos Estatutos de Autonomía ${ }^{45}$. De conformidad a la previsión estatutaria la Ley 4/1984, de 5 de junio, de la Junta General del Principado de Asturias, regula esta competencia de los Ayuntamientos, junto con la iniciativa popular, atribuyéndola a tres Concejos como mínimo, cuyo censo no sea inferior en conjunto a 10.000 electores, aprobada por mayoría absoluta de sus Corporaciones (art. 3.1 Ley 4/1984).

Quedan excluidas de esta posible iniciativa legislativa municipal, aparte de las materias que no sean de la exclusiva competencia autonómica, las de naturaleza tributaria, presupuestaria y operaciones de crédito y deuda pública, la organización y funciones de los órganos institucionales (Junta General, Presidente y Consejo de Gobierno), así como la iniciativa respecto a leyes orgánicas de delegación y transferencia a la Comunidad Autónoma por el procedimiento previsto en el artículo 150.2 CE (art. 2 Ley 4/1984) ${ }^{46}$.

\footnotetext{
45 Tal es el caso de Andalucía (art. 33.2 EA y Ley 5/1988, de 17 de octubre); Murcia (art. 30.1. EA); Castilla-La Mancha (art. 12 EA y Ley 2/1985, de 8 de mayo) y Madrid (art. 15.2 EA y Ley 6/1986, de 25 de junio). El Estatuto de Autonomía del País Vasco reconoce esta atribución en favor de las instituciones de los Territorios Históricos (art. 27.4); Cataluña lo hace respecto de las demarcaciones supramunicipales (art. 32.6 EA) y Canarias y Baleares a los Cabildos y Consejos Insulares, respectivamente. Navarra la atribuye a un tercio de los municipios y un 50\% de la población de derecho (art. 19 L.O. de Reintegración y Amejoramiento del Régimen Foral y Ley Foral 4/1985, de 25 de marzo).

${ }^{46} \mathrm{El}$ art. 2 de la ley menciona así mismo como materias excluidas las referentes a los derechos fundamentales y libertades públicas reconocidas en la Constitución, lo que puede considerarse como redundante ya que su regulación exige ley orgánica y como tal queda reservada al Estado; sobre la cuestión vid. G. Arranz Pomar; Comentario al Estatuto de Autonomía de la Comunidad autónoma de Asturias (Madrid 1987), p. 317 ss. (comentario al art. 31).
} 